\title{
The difficulty of thinking
}

\section{Listening to the voices of students in early childhood education}

\author{
Camilla Kronqvist \\ Åbo Akademi University \\ camilla.kronqvist@abo.fi \\ Birgit Schaffar and Marina Lundkvist \\ University of Helsinki \\ birgit.schaffar@helsinki.fi \\ marina.lundkvist@helsinki.fi
}

\begin{abstract}
This paper addresses the question of how to conceptualise the kind of difficulties students in early childhood education encountered in articulating their thoughts and in listening to others in the initial stages of a CoI. With examples from their course diaries, we illustrate what sense it makes to consider the thinking the CoI promotes as centrally embodied, extended, embedded and enacted (4Es). We consider their difficulties, not as external obstacles to expressing their thought, but as difficulties that are internal to thinking itself, in the sense that thinking implicates the skillful participation in a shared practice that involves us as embodied human beings, enculturated in a context that carries much of the meaning of our situation, engaged in activities that are centrally social, and dependent on interaction with others, who on a fundamental level shape what it is possible for us to think.
\end{abstract}

\section{Key words}

Community of Inquiry, early childhood education, 4Es of cognition, thinking as shared practice 


\section{Introduction}

There is a strong body of research pointing towards the benefits of using methods from P4C for developing critical and creative thinking. Previous studies argue that the Community of Inquiry (CoI) has a positive impact on the communicative and reflective skills of the participants (see e.g. Garcia-Moriyón et al. 2005, Trickey \& Topping 2004). Yet such studies have also been criticized for being limited in their approach. Rather than offering empirical evidence of its benefits, they have been considered as offering 'largely unsystematic reflections on the goals and practices of the practice' (Reznitskaya 2005, p. 4), leaning on anecdotal evidence, self-report, and using forms of measurement that are too dependent on what is taught in the CoI (Garcia-Moriyón et al. 2005).

This criticism of previous research has often argued for better forms of measurement. We, however, submit that an answer to the question whether the CoI advances critical or creative thinking, as was suggested by Matthew Lipman (2009), presupposes a better grasp also of what is meant by thinking. In other words, we stand in need of an increased conceptual awareness of what someone is doing when he or she thinks and what we are doing when we are thinking together. To answer the question whether participants of the CoI learn to become better at thinking we need, as it were, an articulation of what it is they have become better at doing (cf. Lipman 1988), as well as an understanding of the kind of learning involved in this.

Fully answering these questions, of course, is beyond the scope of this article. A first step, however, is to clarify the kind of questions they are. Our first aim, therefore, is to remind us that they are philosophical questions. They involve us, as it were, in conceptual questions about what cases we are to count as thinking, rather than empirical questions about the degree of 'thinking' we can observe in a particular case. Recognising this philosophical and, to some extent, theoretical aspect of our discussion is important. Nevertheless, the philosophical reflections we offer are also practical in at least two ways. First, the writing of this article involves us in a practice in which we elucidate our understanding of some aspects of what is involved in thinking and learning. Second, our reflections, though in some way not dependent on empirical observations, were inspired by considerations of observations made in conducting a CoI with a group of students in early childhood education. In aid of our philosophical reflections, we therefore explore some examples from this study and draw on experiences from it. We do not, however, present conclusive results from this study, neither do we attempt a strictly theoretical exposition of problems that emerged to us 
in the study of (theoretical or philosophical) texts and thoughts. At the risk of this approach being understood as insufficiently attending to either one of these traditional ways of conducting a study, both the content of our article and its form are meant to emphasise that reflection is at the same time practical as well as philosophical.

Our leading question is: how we should conceptualise the kind of thinking that we encounter in our empirical study? In order to do this, we first provide a short presentation of it and give four examples of difficulties that the students describe in relation to the CoI. We then use these and other examples as a background and a source of illustrations, against which to delve deeper into philosophical questions concerning the embodied, extended, embedded and enacted character of thinking (Menary 2010). Here we draw on arguments from various theoretical and philosophical approaches, which by commentators have been gathered under the heading of the four Es of cognition. Our discussion lends support to the notion that thinking, rather than being an inner, mental process, engages us in a shared practice in which standards need to be established and explored concerning what it means to think well and to think better.

\section{Student's initial difficulties in thinking}

The examples we lean on stem from a short-term study we conducted with Finnish university students in early childhood education. In it, we introduced methods, in particular the Community of Inquiry (CoI) from Philosophy for Children (P4C, see Lipman 2003, 2009; Stanley 2012), or Philosophy for Schools, to critically examine whether including analytical tools for thinking would further their reflective thinking. The first author (Kronqvist) worked with the students for ten hours, spread out over five occasions in one of the students' regular courses. Each session followed a similar pattern, where 20-30 minutes at the beginning were dedicated to introducing methods from $\mathrm{P} 4 \mathrm{C}$. The remaining 60-70 minutes were used to practice these methods. At centre stage of this practice was the CoI, a semi-structured form of conversation developed within P4C to strengthen, among other things, the communicative and reasoning skills of the participants.

Our version of the CoI followed the scheme of a short introductory object; a text, a film, a children's story book, or a transcript of a conversation with children (Stanley 2012, pp. 147-148), individual time for thinking of questions, the collection and choice of question and a discussion followed by a meta-conversation. The discussion was 
moderated by Kronqvist who distributed turns to speakers, so that everyone at all times should feel ready to contribute to the common discussion. Kronqvist also raised questions aimed at improving conceptual awareness (Stanley 2012, pp. 159-160). These questions included asking for examples of situations in which certain questions would arise, asking whether the participant agreed or disagreed with the previous speaker, and whether they could provide reasons for their view, requests to summarise what the previous speaker or they themselves had said, whether they had asked one or two questions, or to judge in what respects one question was similar or different to another question. The meta-conversation, often given as much time as the discussion, had a freer format, where the focus was to reflect on thoughts that arose during the discussion and on how well the discussion had helped to answer the initial questions. At times Kronqvist, as moderator, would also point out certain greater philosophical themes that arose in the discussion to show their connection to the initial question.

During the course, the students were asked to reflect on the practice by writing short course book diaries after each session. The questions they were asked to respond to were (1) 'What was rewarding?' (2) ‘What was challenging?' (3) ‘What aspects do you want to develop'? The pedagogical aim of these questions was to make the students reflect on their own learning, to make them aware both of what they have learned and what they still needed to learn. Thus, it was interesting to record how the students, in response to the first and the third question, expressed an interest in discussing issues concerning their professional roles, and found it rewarding to listen to others, especially to participants who normally would be more silent. They also expressed the desire to become better at actively listening to others, and to articulate themselves more clearly. This could be seen as the first step in becoming aware of aspects of thinking and reasoning with others that they wanted to practice as part of their future work. Considering the significance that dialogue and listening is accorded in their training (e.g. Bae 2012; Pramling Samuelsson \& Asplund Carlsson 2008), it is also not surprising that they would value such aspects of the CoI.

Yet, we were surprised to see in these diaries how much time the students spent on responding to the second question and the kind of challenges the practice posed for them. These reflections also extended to the third question, as they often phrased what they wanted to develop in relation to what they perceived as challenging. Although the material was limited, eight course diaries in total, the reporting of these challenging experiences brings out a set of difficulties that we want to consider more closely. As a more general illustration of these challenges, we here list four initial difficulties in becoming acquainted with the practice that we see in their course diaries. 
For each difficulty we present three translated quotes from three different students to provide examples of what they said.

(1) Focusing on the questions asked and attending to what was said:

I would like to develop my ability to sit back and listen, I focus very much on presenting my own opinions and my own way of thinking.

The most challenging aspect of today's occasion was to keep myself focused on the task at the same time as I analysed the answers of the other participants.

In the moment I have to concentrate on remembering what the others are saying, and what I want to say and what the question was. It sometimes feels frustrating to forget the thought.

(2) Being caught up in their own thoughts while supposed to listen to others:

One easily loses the thread if one sits and thinks at the same time [...] it is difficult to listen at the same time as one is preparing a response.

I would like to ... be able to turn off my own thoughts and associations and instead only focus on the content of what the person is saying.

It was difficult to focus on something that I thought we had already discussed and not talk about what I was thinking of.

(3) Feeling frustration at not being able to express themselves clearly when asked a question:

It is also not so easy to present one's own thoughts in a clear and understandable manner.

Spontaneously responding to questions and expressing oneself in the right way, and preferably quickly, is still challenging.

When one heard the question many thoughts and ideas 'popped' up in one's head and one thought one had the question in grip. But when one was supposed to express one's thoughts in words it wasn't as coherent as one thought. It wasn't so easy to collect one's thoughts and say what one wants in a logical manner. 
(4) Not being called upon when they felt they had something to say

There were also times when one dearly wanted to say something because one had a really good thought that belonged together with what was discussed, but if one didn't have the speaking turn, the discussion went off in another direction and the thought wasn't discussed.

I realised that I easily gave up the question if I didn't know what to say. But directly after passing the speaking turn to someone else, I want to say something and then it's too late.

I hope [...] I can get away from the thought of always focusing on getting my own point across.

Since their practicing of the CoI was quite short, it is probable that the students would overcome many of these difficulties with more practice. The diaries also suggest that they became more comfortable with the practice the further on it went. However, since part of our interest in considering these issues is to reflect on what is entailed in learning to think, turning to the question of what difficulties the students encountered in the beginning of learning the practice offers an interesting view into what they had to learn.

Thus, the following discussion turns on the question of how we should make sense of these (at least initial) difficulties in relation to thought. The question we want to pursue is whether we should conceptualise these difficulties as internal or external to thought. Are they to be seen as external obstacles to thinking, or are they to be seen as internal to thinking itself? Are they, say, concerned with the students' failure to express their thoughts, or do they reveal to us a more fundamental aspect of their ability to think?

In the following section, we argue that there are considerable advantages of regarding them as internal to thought, and thus perceiving thinking as entrenched in different forms of practices to which one needs to become accustomed to be able to think. We first present a short background to the philosophical commitments entailed in regarding these difficulties as internal to thought, and then discuss how these difficulties can meaningfully be said to lend support to that view. Since we are working with a certain pre-given understanding of what we are to consider as thought in our explications of these difficulties as difficulties in thinking, there is a degree of circularity in our discussion. In line with the hermeneutical tradition, however, we 
submit that such a circularity is not to be avoided, and that it can still benefit our understanding of what we can meaningfully think of as thinking.

\section{Questioning the mentalistic conception of thinking}

$4 \mathrm{E}$ cognition is a name used for an interdisciplinary field of research collecting researchers in neuroscience, psychology, psychiatry and philosophy (Newen, De Bruin \& Gallagher 2018). The four Es stand for Embodied, Embedded, Extended and Enacted. It is used as an umbrella term for various approaches, and within these, there is no clear agreement on what Es are to be counted or how they should be understood (see Kiverstein \& Clark 2009; Menary 2010 for an overview of some debates). All approaches, however, come together in a criticism of a mentalist conception of cognition. According to this conception, cognition consists (or is to be equated with) internal mental processes, today often equated with neural processes in the brain, and can be considered as a matter of constructing and manipulating mental representations. The $4 \mathrm{E}$ approaches rather aim at conceptualising the necessary interactions between the brain, the body, and both the physical and social environment as well as the connection between cognition, language and culture (Newen, De Bruin \& Gallagher 2018). In this, they share an affinity with several philosophical critiques towards the mentalistic picture of both the mind, and thinking, taken more broadly than as a direct interest in cognition. This criticism has come from phenomenology (Leder 1990; Ratcliffe 2008; Noë 2012), ordinary language philosophy (Hamlyn 1990; Hertzberg 2007; Crary 2016), and the pragmatism and social learning theory that partly inspired the methods Matthew Lipman developed for P4C (Dewey 2007; Vygotsky 1978). Many of the philosophers who can be said to be working in relation to the $4 \mathrm{Es}$ also have a background in these traditions (e.g. Ratcliffe 2008; Noë 2012; Hutto \& Myin 2012).

None of these approaches deny that speaking about someone as thinking implies that certain neural processes take place in the brain (cf. Davidson 1980, p. 214). Neither do they question that there may also be significant empirical results coming out of neurology and psychology from studying these processes. However, they are reluctant to commit to an account of thinking that reduces speaking about thinking (Hertzberg 2007) to the reporting of cognitive processes (conceived as neural processes) expected to take place in our brain. Therefore, they also raise several important methodological questions about the extent to which we are to think of the mind as similar or reducible to the brain (Churchland 1993), and the ways in which the notion of a 'mental process' 
is construed in diverging theoretical frameworks. Are we, for instance, entitled to consider a mental process as discussed in philosophy as the same as a cognitive process in psychology, or a neural process in neurology? To what extent are these construals shaped by the particular questions one seeks to answer in different fields and studies? (cf. Longino 2012).

Furthermore, these criticisms have shown how the mentalistic conception lands us in central philosophical problems, such as a mind-body dualism, and a mind-world dualism. Within this dualist framework, the task becomes to explain how it is possible for the mind to interact with the body, or the mind to interact with the outside world, whereas these critics in different ways have shown that speaking of thought in the first place presupposes the forms of interaction the mentalistic conception is anxious to explain.

What is central to our concern with these debates is that the reductionism entailed in the mentalist conception makes it difficult to conceive what is meant by becoming better at thinking. It does not as John Dewey already puts it, allow us to distinguish between 'idle' and 'reflective thought' (1910, pp. 2-4). This distinction relies on the difference between the thoughts that flow through our minds, the daydreaming, and the thought put to use, the thought that is also prepared to turn in on itself, to subject itself to analysis and criticism (cf. Dewey 1910, p. 6). The ability to make such distinctions is central to philosophy. Even to speak of idle thought as a form of daydreaming or fantasy, as something that can be articulated in thought and placed in the context of memories, places and interpersonal relationships, takes this kind of thought beyond the neurological processes in the brain reported in terms of cognition or mental processes.

\section{The four Es in thinking}

In the following, we will use the four Es as analytical tools to illuminate central, but sometimes overlapping, features of the thinking the students can be said to have learned, and the ways learning to think perceived in this way may be experienced as difficult. This will allow us to describe the student's difficulties in expressing themselves, in listening and responding to each other as difficulties of thinking. 


\subsection{Embodied}

The notion that cognition is embodied, reminds us that cognition is not only a process in the brain, but involves us in different forms of bodily responsiveness (Johnson 1987). As a first step, this can be taken as a reminder that cognition is not only dependent on neural processes in regions of the brain that are associated with higher cognitive functions but also on the activation of the amygdala, associated with affective responses (LeDoux 2003). It is also a reminder that cognition does not only depend on neural processes in the brain, but on the whole body, such as the activation of the autonomous nervous system, the senses and so on (Ward \& Stapleton 2012). This can be taken to imply that cognition cannot be reduced to neural processes in the brain, but that they are only a limited part of the whole system that makes up the organism that a human being is. However, this may still leave us with the picture that cognition is really the neural processes, although embedded within a greater biological system (the body), and that we can conceive of the process of understanding another person's thought as a matter of reaching these hidden inner processes (cf. Malcolm 1986).

However, in our ordinary ways of speaking, in which thinking rather than cognition is the central word, it is important to acknowledge that we do not attribute thinking to the brain, but to the whole person (cf. Cockburn 2009, 2012). It is not the brain that does the thinking, but the fully embodied human being. When the students, for instance, were asked to tell each other what they thought, the interest was not in whatever processes went on in their brains, but in what they had to say in response to a question. Furthermore, when they emphasised the need to listen actively to what others were saying, they did not suggest that listening. in the bare sense of registering the sounds the others make, and which can be brought down to airwaves, would be enough. Reducing thought to neural processes thus gives a too mechanical understanding of what is involved in attending to someone's thought. Here, the significance of considering us as embodied beings to be able to make sense of thought, rather lies in reminders such as that what someone says cannot be disconnected from how they, as embodied beings, say it, and how this is received by others who are equally embodied.

Thus, it is not coincidental that the students articulate their difficulties of not being able to speak in the form of embodied experiences of discomfort, frustration and disappointment. Similarly, they felt at ease when they could express themselves in the way they desired. They also reacted to each other's struggles, expressed in their embodied responses, with feelings of reassurance and relief in recognising that the 
other participants also had problems expressing themselves, and that they were affectively engaged in similar questions as they themselves.

These ways of spontaneously responding to each other are again not to be seen as hypotheses about what went on in their heads. To be able to say that the students recognised that others were 'struggling with similar questions', or 'showed interest in them', we are not committed to thinking that they first, as it were, registered bodily movements, and then inferred thoughts and intentions behind them. We do not need to say that they drew conclusions about the others' inner states by considering their outer behavior, but can simply note that they responded to each other, and what they were saying, as well as the way they were saying it, in these meaningful ways (Cockburn 2009). In other words, they immediately perceived, a few sessions on, that 'it felt as if they had grown better in responding', as one student wrote. They were also able, in the final discussion, when each speaker was allowed to decide who would take the next turn, to pass the speaking turn to someone who looked as if they were going to say something, and also to use looks to communicate their desire to speak next. The difficulties that students express in participating in the discussion with their own thoughts, are in this sense partly to be understood as related to embodied responses to the situation.

\subsection{Embedded}

The notion that cognition is essentially embedded is close to the sense in which it is embodied, and refers to the way in which cognition is always situated in a particular context. Cognition, in other words, is not only related to the whole organism, but the organism in turn only functions within an environment, a surrounding world (Ward \& Stapleton 2012; Ratcliffe 2008). If we again move from talking about cognition to speaking about thinking, we can here consider how, for human beings thinking typically entails the surroundings of a culture and technology that allows us to enhance our thinking in specific ways. In particular, we may consider the ways in which thinking is dependent on language. A first possible way of describing this dependence is to say that language provides the means of communicating our thoughts. This, however, again suggests that thoughts are internal processes, whereas the linguistic expressions of thought are external to these processes. A better way of articulating this dependence, then, is to say that language is a pre-requisite for articulating thoughts (Cockburn 2012), to such an extent that we can only be said to 
know what we are thinking if we are able to articulate our thought (Schaffar 2014, p 15).

Part of the difficulties the students were experiencing can be seen as a difficulty in articulating their thoughts in response to a specific question, as well as to acknowledge that their thoughts were not as articulate to them as they would have hoped. Interestingly, as some of the students notice, this may not be as apparent in 'in an ordinary conversation or in a lecture'. Whereas these offer opportunities to sit back, to listen to others or to 'get caught up in a detail without concern for the whole', the speaking turns that were distributed at random alerted them to their own failure at times to express their thoughts on command. They realised that they failed to say something because they did not have something to say at that distinct moment, or because they wanted to speak on another topic, or because they were caught up in thinking about something that had previously been said, or because they did not understand the question. This failure to express themselves clearly is interesting in itself because it shows that saying what one thinks does not involve a mere registering of what is going on right now in one's mind, but requires attentiveness to and a judgement of how what one says bears on the present situation. To some extent it even asks them to develop new ways of expressing their thoughts.

\subsection{Extended}

The sense in which cognition is extended (Clark \& Chalmers 1998), is close to the sense in which it is embedded, but emphasises the dynamic relationship between the being and its environment, and the sense in which the environment offers affordances for thinking. Think only of how differently we move about in familiar surroundings and in a new environment (Leder 1990). The students' initial reactions to the philosophical conversation can here be seen as a reaction to having to interact in an environment that was unfamiliar to them, in that they did not know what was expected of them.

The extended character of the thought is also witnessed in the role different forms of tools and skills, such as writing, have for thinking, not just as a medium for one's thought but as extensions of them. Collecting questions and writing them on the board, for instance, enabled the students to consider their differences and similarities to a much greater extent than when thoughts and questions were uttered orally. Here the students repeatedly showed difficulties in remembering and summarising what had just been said, even by themselves, or to compare two suggestions for how to articulate 
a question. A couple of students also worried in their writing that they would not remember what was said in the discussion if they did not write it down.

Nevertheless, some students also noted that it was easier to partake in the discussion when they were not taking notes, but actively following the discussion instead of thinking about what they would write down later. One student writes, 'The most rewarding aspect today was that I left out my notebook. It was easier for me to concentrate during the discussion'. This suggests that one's thinking can rely on different forms of support, and that the structure of the CoI, as well as the facilitator's questions, also had a supportive role in the students' thinking. After practicing this new routine on several occasions, the students said that it became easier to follow the rules of the conversation. When they started to have an idea of what questions they could be asked, they were better prepared to listen to what others said, in search of cues that might lead them to their next statement.

\subsection{Enacted}

The fourth dimension expands on the others and reminds us of ways in which cognition, or the mind more generally, is not only dependent on embodied reaction, or environmental or social interaction, but involved in different forms of action (Hutto \& Myin 2012; Noë 2012). Thinking does not only concern neural processes within us, but is constitutively a matter of what we do. It involves us in skillful activity, where acting skillfully is not reducible to the manipulation of mental representations in the brain. Rather the task of thinking through an issue is to be considered both an activity itself, and as a possible precursor to other actions.

In the context of the CoI, learning to think better can be seen as the outcome of practicing a skill or training a new habit. As David Kennedy writes, in relation to Dewey's notion of educative experience, the CoI 'exemplifies and models a form of reason that, grounded as it is in the concrete lived experience of oral dialogue and rigorous mutual and self-interrogation, is an affective and social process of collaborative concept construction' (2012, p. 38). Thus, it engages the students in a practice within a set context with explicit rules, as embodied human beings. It involves them in forms of reflection, and significantly self-reflection, that essentially happen in interaction with each other, and that may occasion changes in attitude that entail their embodied responsiveness, and also how they go on acting and conducting conversations in the future. 


\section{A possible fifth $E$}

Above we connected the initial difficulties the students had in engaging in the CoI with aspects of thinking brought forth in theories about $4 \mathrm{E}$ cognition. According to this view, thinking is fundamentally enacted in conversation with others. This also gives a pointer towards what the students can be expected to do better, as they learn this practice. As soon as we see people as engaging in practices, as it were, we are asked to make a judgement as to whether they are actually doing what they are supposed to be doing, or whether they are doing it well (cf. Børresen 2013). In the case of the CoI, we may therefore ask, whether they are engaging in the '[a]ctive, persistent, and careful consideration of any belief or supposed form of knowledge in the light of the grounds that support it, and the further conclusions to which it tends' that to Dewey $(1910$, p. 6) is a characteristic of reflective thought?

To account for this feature of the thinking that one can aim for in the CoI, we want to raise a final question about the extent to which this thinking also raises questions about a fifth $\mathrm{E}$, that is, places on us demands that in a broad sense can be regarded as ethical (cf. Crary 2016). This is not to be taken in the narrow sense that it should provide moral rules for actions, but rather in the sense of considering how one attends to the standards inherent in a practice as well as to others. This gestures at two distinct aspects of what can be perceived as ethical. The first is the sense in which thinking is evaluative. In other words, it involves us in making judgements that can be evaluated as good in the sense of more or less appropriate, meaningful and insightful. The making of such judgements itself is practiced in the CoI. It involves the interrogation about what it means to think certain things, and whether a form of thinking is good if it leads to undesirable conclusions. In the CoI the students were invited to consider that whatever words they uttered in response to a certain question would not yet constitute a response to that question, not to say a good response. Rather they were asked to take a stand on whether they were adequate responses in relation to the questions asked. Furthermore, the meta-conversation raised questions about the ways in which they had engaged in the conversation. Did they provide good answers to the questions, in the sense of providing good grounds for holding certain views? (cf. Børresen 2013). They were, of course, in different ways also invited to consider in what sense it is possible to speak of good grounds for holding a view, and the different standards for what is to count as 'good' in different cases. 
There are concerns that such emphasis on standards for evaluating thinking conveyed in the CoI privileges certain understandings of what thinking is. Walter Kohan suggests that understanding 'philosophical thought as a set of abilities or tools condemns it to the mirrored repetition of the same-if not of the same content, at least of the same model of thinking' (Kohan 2014, p. 40). This, he suggests, deprives us of the sense in which, 'Philosophical thinking is not an ability, but an event; not a tool, but an experience' (Kohan 2014, p. 40). We cannot delve deeper into this question here, but we want to emphasise that the practices of $\mathrm{CoI}$ in our understanding are not aimed at providing any pre-given model of reasoning, or an external general standard for assessing what a good thought might be. Rather, there is a certain open-endedness in the question of what in relation to a specific question is to be considered a good way of responding to it. Answering that question in turn requires sensitivity on the part of the participants to respond to the particulars of the conversation, and to each other, and to articulate their understanding of what would be a good way of answering a question in that light.

This brings us to the second sense in which the practice of the CoI can be seen as raising ethical demands. It involves us in an encounter with other human beings, which is constituted not only by forms of interaction, but also by a kind of attunement (Johansson 2010, p. 470). The CoI involved the students in a confrontation with others, with different sets of ideas, different ways of understanding a question, which in turn confronted them with their own thoughts, and a consideration of how they would align with others, and with the conversation at hand. At its best, the CoI offered an opportunity for the students to listen to these other voices, and to be present to what was happening in this meeting. The students experienced how difficult such presence to others might be and raised questions as to whether it was really possible to both think of what to say themselves, and to listen to others. Yet, at times, their initial concern for themselves, and how well they were able to present themselves to others, also appeared as an obstacle to their partaking in the form of communal thinking the CoI offered. The students' pre-occupation with how well they were able to express their thought, and their desire to only do so when they felt comfortable, hindered them from responding to what can be seen as the moral demands of a conversation, or a dialogue, i.e. to respond responsibly to what others are thinking by attentively listening to them, and to attend to the issue at hand. In such ways, it also hindered them from developing their own voice. 


\section{Conclusion}

In our discussion, we have explicated what may be entailed in thinking of the difficulties of our students, not as external obstacles to expressing their thought but as difficulties that are internal to thinking itself, in the sense that thinking involves the skillful participation in a shared practice. Rather than thinking of thought as an inner process, we have elaborated a conception of thinking that involves us as embodied human beings, enculturated in a context that carries much of the meaning of our situation, engaged in activities that are centrally social, and dependent on interaction with others who, on a fundamental level, shape what it is possible for us to think.

To be able to think of what it could mean to become better at thinking, we therefore need to attend to what the students learn through engagement in the practice of $\mathrm{P} 4 \mathrm{C}$ and with each other, as well as attend to what is involved in overcoming the initial difficulties they experience. This may involve attention to growing experiences of comfort in becoming more accustomed to the practice, a propensity to endure discomfort, occasional silences and confusing moments, as well as a recognition that their first thoughts may well be provisional and subject to change as the conversation progresses. Yet it involves them in the recognition that they still need to take the questions seriously, as well as show willingness to subject themselves to such change and scrutiny. In these senses, the training in thinking that the CoI promotes is dependent on a growing awareness by its participants of what in this practice and in a particular conversation can be considered as constituting good forms of reasoning. The CoI itself creates the environment in which thoughts arise, are mirrored by others and judged.

This makes it difficult to judge whether someone has learnt to be better at thinking, and even more to establish any intersubjectively verifiable empirical criteria for what constitutes an improvement in a person's thought. Certainly, one may, as has been done in previous studies, attempt to see whether participating in the CoI also has effects on the students' results on other tests in e.g. mathematics and languages (cf. Trickey \& Topping 2004). Nevertheless, whatever results such measurements show, they do not speak to the sense in which the students of the CoI may think of themselves as becoming better in responding to each other and becoming more aware of their responsibility for what they are saying. To be able to judge a chain of reasoning as good in this sense, they, as it were, need to develop into becoming more reasonable persons (Johansson 2018, p. 1154). Engaging in such a task itself raises ethical questions 
as to what we can regard as good and meaningful in our life with others, and the particular conversations in which we are involved.

\section{References}

Bae, B (2012) Children and teachers as partners in communication: Focus on spacious and narrow interactional patterns. International Journal of Early Childhood, 44(1), pp. 53-70.

Børresen, B (2013) Foreword. In MB Glina (ed) Philosophy for, with, and of children. Cambridge, UK, Cambridge Scholars Publishing, pp. vii-xi.

Churchland, PM (1993) Evaluating our self conception. Mind and Language, 8(2), pp. 211-222.

Clark, A \& Chalmers, D (1998) The extended mind. Analysis, 58(1), pp. 17-19.

Cockburn, D (2009) Emotion, expression and conversation. In Y Gustafsson, C Kronqvist \& M McEachrane (eds) Emotions and understanding: Wittgensteinian perspectives. New York, NY, Palgrave, pp. 126-144.

Cockburn, D (2012) Ethics and language: What we owe to speakers. In N Forsberg, M Burley \& N Hämäläinen (eds) Language, ethics and animal life. New York, NY, Bloomsbury, pp. 32-44.

Crary, A (2016) Inside ethics. Cambridge, MA, Harvard University Press.

Davidson, D (1980) Essays on actions and events. Oxford, UK, Clarendon Press.

Dewey, J (1910) How we think. Boston, MA, DC Heath \& Co.

Dewey, J (2007) Democracy and education. Teddington, UK, Echo Library.

Garcia-Moriyón, F, Rebollo, I \& Colom, R (2005) Evaluating Philosophy for Children: A meta-analysis. Thinking: The Journal of Philosophy for Children, 17(4), pp. 14-22.

Hamlyn, D (1990) In and out of the black box: On the philosophy of cognition. Oxford, UK, Blackwell. 
Hertzberg, L (2007) The importance of being thoughtful. In D Moyal-Sharrock (ed) Perspicuous presentations: Essays on Wittgenstein's philosophy of psychology. New York, NY, Palgrave, pp. 50-74.

Hutto, D \& Myin, E (2012) Radicalizing enactivism. Basic minds without content. Cambridge, MA, The MIT Press.

Johansson, V (2010) The philosophy of dissonant children: Stanley Cavell's Wittgensteinian philosophical therapies as an educational conversation. Educational Theory, 60(4), pp. 469-486.

Johansson, V (2018) Philosophy for children and children for philosophy. Possibilities and problems. In A Chinnery, V Johansson \& N Hodgson (eds) International handbook of philosophy of education. Dordrecht, Springer, pp. 1149-1161.

Johnson, M (1987) The body in the mind. Chicago, IL, University of Chicago Press.

Kennedy, D (2012) Lipman, Dewey, and the community of philosophical inquiry. Education and Culture, 28(2), pp. 36-53.

Kiverstein, J \& Clark, A (2009) Introduction: Mind embodied, embedded, enacted: One church or many? Topoi, 28, pp. 1-7.

Kohan, W (2014) Philosophy and childhood: Critical perspectives and affirmative practices. New York, NY, Palgrave.

Leder, D (1990) The absent body. Chicago, IL, The University of Chicago Press.

LeDoux, J (2003) The emotional brain, fear, and the amygdala. Cellular and Molecular Neurobiology, 23(4/5), pp. 727-738.

Lipman, M (1988) Critical thinking-What can it be? Educational Leadership, 46(1), pp. 3843

Lipman, M (2003) Thinking in education. Cambridge, UK, Cambridge University Press.

Lipman, M (2009) Philosophy for children: Some assumptions and implications. In E Marsal, T Dobashi \& T Weber (eds) Children philosophize worldwide. Theoretical and practical concepts. Frankfurt am Main, Peter Lang, pp. 9-23.

Malcolm, N (1986) Nothing is hidden. Oxford, Blackwell. 
Longino, HE (2012) Studying human behavior. Chicago, IL, Chicago University Press.

Menary, R (2010) Introduction to the special issue on 4E cognition. Phenomenology and the Cognitive Sciences, 9(4), pp. 459-463.

Newen, A, de Bruin, L \& Gallagher, S (eds) (2018) The Oxford handbook of 4E cognition. Oxford, UK, Oxford University Press.

Noë, A (2012) Varieties of presence. Cambridge, MA, Harvard University Press.

Pramling Samuelsson, I \& Asplund Carlsson, M (2008) The playing learning child: Towards a pedagogy of early childhood. Scandinavian Journal of Educational Research, 52(6), pp. 623-641.

Ratcliffe, M (2008) Feelings of being. Phenomenology, psychiatry and the sense of reality. Oxford, UK, Oxford University Press.

Reznitskaya, A (2005) Empirical research in philosophy for children: Limitations and new directions. Thinking: The Journal for Philosophy for Children, 17(4), pp. 4-13.

Schaffar, B (2014) Changing the definition of education. On Kant's educational paradox between freedom and restraint. Studies in Philosophy and Education, 33(1), pp. 5-21.

Stanley, S (2012) Why think? Philosophical play from 3-11. London, UK, Continuum.

Trickey, S \& Topping, KJ (2004) 'Philosophy for children': A systematic review. Research Papers in Education, 19(3), pp. 365-380.

Vygotsky, LS (1978) Mind in society. Cambridge, MA, Harvard University Press.

Ward, D \& Stapleton, M (2012) Es are good: Cognition as enacted, embodied, embedded, affective and extended. In F Paglieri (ed) Consciousness in interaction: The role of the natural and social context in shaping consciousness. Amsterdam, John Benjamins, pp. 89-104. 